\title{
CO-MOVEMENT AMONG WORLD VEGETABLE OIL PRICES: A WAVELET-BASED ANALYSIS
}

\author{
Abdul Hafizh Mohd Azam • \\ Bank Negara Malaysia \\ Tamat Sarmidi* \\ Universiti Kebangsaan Malaysia \\ Abu Hassan Shaari Md Nor \\ Universiti Kebangsaan Malaysia \\ Muhamad Rias K V Zainuddin \\ Universiti Malaysia Terengganu
}

\begin{abstract}
This paper examines the co-movement among major world vegetable oil prices (palm, soybean, rapeseed, and sunflower oil) by using wavelet-based analysis for a dataset ranging from January 2003 until March 2018. The wavelet approach is superior to the other techniques as it provides a flexible tool in investigating the changes in time and frequency domain simultaneously. The empirical result shows that the strong comovement among vegetable oils are driven by strong contagion and interdependence but incomplete vegetable oil market integration among major world vegetable oil. Interestingly, palm oil shows a lower degree of relationship with other edible oil in all scales after 2015. Meanwhile, more recent data shows that soybean and rapeseed oil have shown an increase in interdependence among each other. The study finds that multiple cross-correlations indicate that soybean oil is a potential leader of the vegetable oils market followed by palm oil primarily in the low scale period. This study on the time-frequency domain gives new insight for traders and investors in the vegetable oil market relating to the strategy for portfolio diversification and risk management.
\end{abstract}

Keywords: Vegetable oil markets, contagion, interdependence, wavelet coherence, wavelet multiple crosscorrelations

Received: 10 March 2020

Accepted: 14 September 2020

\section{INTRODUCTION}

The vegetable oil production has increased from 177.18 million metric tonnes in 2014/2015 to 198.68 million metric tonnes in 2017/2018 - again for about 21 million metric tonnes (United States Department of Agriculture, 2018). Meanwhile, from the total of current production, palm

\footnotetext{
- The views expressed in this paper are the authors' and should not be interpreted as those of Bank Negara Malaysia.

- Coresponding author: Associate Professor, Center for Sustainable and Inclusive Development, Faculty of Economic and Management, Universiti Kebangsaan Malaysia, 43600 Bangi, Selangor, Malaysia. Phone: +603-8921 3448; Fax: +603 8925 1821; Email: tamat@ukm.edu.my
} 
oil contributes a large portion with $35 \%$, followed closely by soybean oil at $28 \%$, rapeseed oil at $15 \%$, and sunflower oil at $9 \%$ (refer Figure 1). In the context of domestic consumption, there is not much difference in the percentage of domestic oil consumption compared to their production. Palm oil has a portion of $34 \%$ from a total of 191.42 million metric tonnes followed by the others.

Figure 1: Major Vegetable Oil Production and Domestic Consumption (\%) in 2018

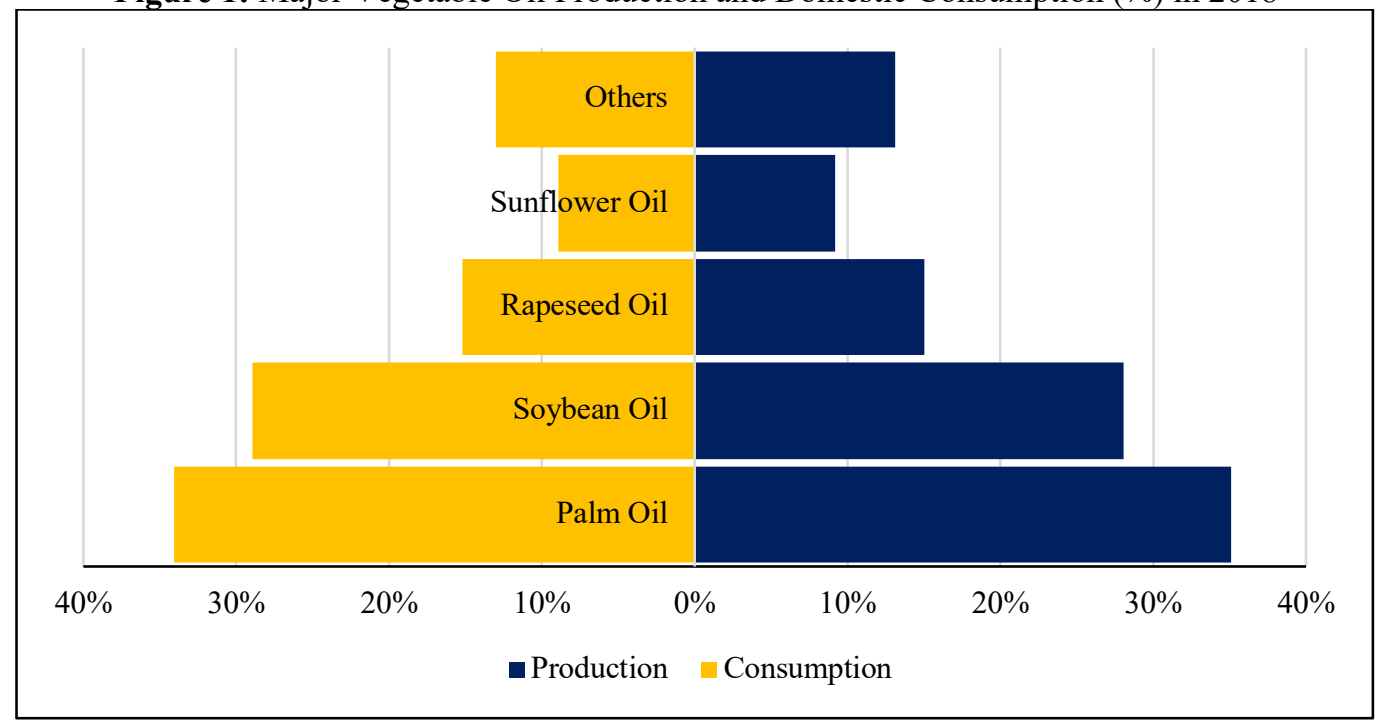

Source: United States Department of Agriculture (2018).

It is a fact that vegetable oil could be substituted with another vegetable oil due to their similar end-use, for example, in the cooking and food industry (Owen, Chowdhury, \& Garrido, 1997). Given the higher interchangeability among the vegetable oils, the question on the co-movement among them is beneficial for producers and investors to gain a benefit in the fluctuation of the price. Classical economic theory state that the price of the goods is determined by the supply and demand in the market.

However, in the world with substitutability are much easier, and the competitor prices are much lower, it is really difficult to meet the assumption of the theory. Perhaps, there might be one vegetable oil that can lead to the price of others. Therefore, relying on the movement of one oil eventually could predict the movement of other oils. Referring to Figure 2, the co-movement of selected vegetable oils price seems to move in the same direction over the long-run, although there is some deviation in the short-run. However, what causes the strong co-movement among the vegetable oil and how well the vegetable oil market is integrated remains a question.

Figure 2 shows a graphical plot of vegetable oil prices from January 2003 until March 2018. It can be seen that all prices seem to move in the same direction over the long-run even though there is some deviation in the short-run. Therefore, what causes the strong linkages among the vegetable oil? Is it due to contagion or interdependencies? Thus, to answer this question, we need to consider the frequency domain analysis. 
Moreover, Figure 2 shows that two main events that cause the price of v'egetable oil hikes up above their normal condition which is during 2007-2008 and 2010-2011. Both events are related to the food crisis, but the main causes of the increase in the price are different. While the former is due to increases in the price of crude oil which eventually increases the cost of transportation, machine operation, and fertilizer (Wiggins \& Levy, 2008) the latter is due to the imbalance of the supply and demand in cereal (Coulibaly, 2013). Besides, from the graph below, palm oil shows relatively lower price compared to other vegetable oil prices.

Figure 2: Price of soybean, sunflower, palm, and rapeseed oil (USD per metric tonnes)

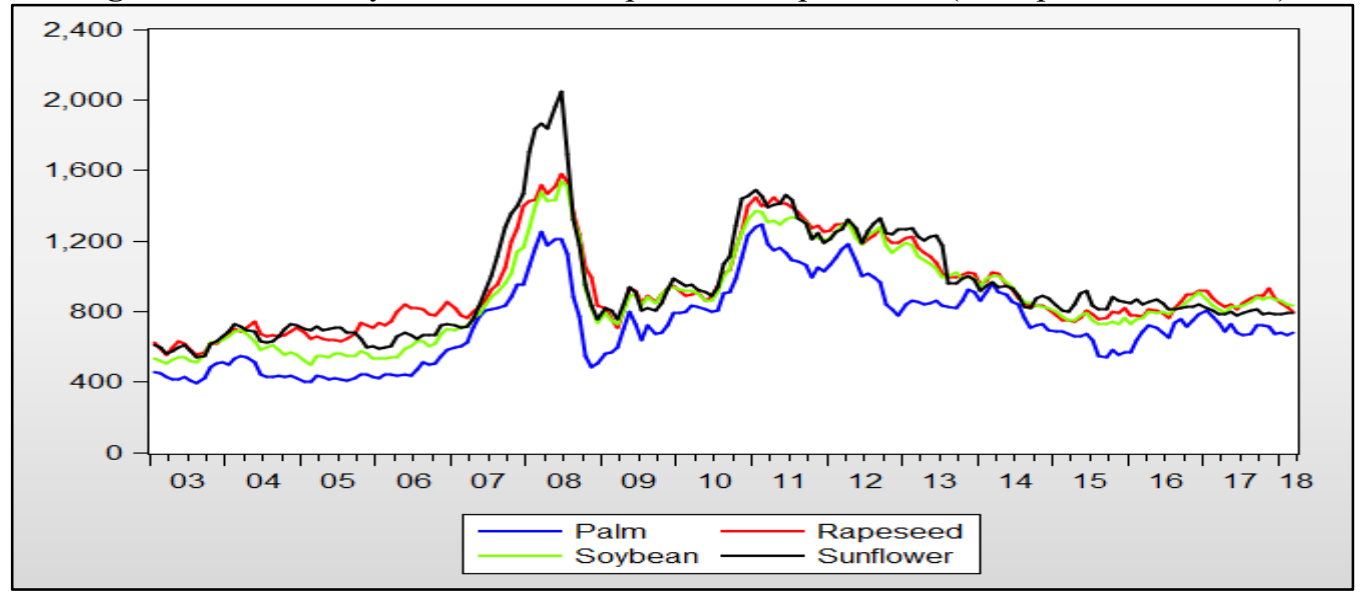

Source: United States Department of Agriculture (2018).

This paper aims to investigate the co-movement among primary world vegetable oil prices by using a more flexible method which is wavelet analysis. In this study, we briefly discuss the issue of contagion and interdependence following the study by Orlov (2009) and Bodart and Candelon (2009) who discriminate the two terms depending on the frequency domain, i.e. low scale (high frequency) and high scale (low frequency). According to Dewandaru, Rizvi, Masih, Masih, and Alhabshi (2014), a low scale can be defined as a period below than one year and a high scale as a period above one year. Therefore, a sudden increase in co-movement in the low scale can be associated with the contagion while the increase in co-movement in the high scale can be associated with interdependence.

On the other hand, contagion can be referred to as pure contagion and interdependence can be referred to as fundamental-based contagion (Bodart \& Candelon, 2009). The term pure contagion generally reflects the temporary increase in the co-movement due to investors behaviour such as financial panic, herding, and loss of confident (Gallegati, 2012) while the fundamental-based contagion can be referred as real linkages in both crisis and non-crisis period (Calvo \& Reinhart, 1996). Therefore, in order to determine the changes in the co-movement across time and scale, we follow the study by Madaleno and Pinho (2012) and Dewandaru et al. (2014) by applying continuous wavelet transform (CWT). 
This paper contributes in two different ways. First, this paper investigates the co-movement among the major vegetable oil by differentiating the movement into two part which is pure contagion or fundamental-based contagion. Secondly, this paper applies a recent econometric technique namely wavelet analysis which is a very flexible tool in handling non-stationary data while at the same time allow the analysis of both time and frequency domain simultaneously. The paper is organized as follows: Section 2 discusses the previous literature regarding the co-movement of vegetable oil and the application wavelet analysis. Section 3 focuses on the data and methodology part while section 4 provides evidence on the linkages among vegetable oil. Section 5 concludes the paper with some applications in investment.

\section{LITERATURE REVIEW}

Previous literature has been documented the co-movement among vegetable oil prices itself or vegetable oil with other commodities like crude oil. However, the evidence is rather mixed than unique which may depend on the econometric technique, data spanning, and variables that have been used. One of the earliest works on the co-movement of the vegetable oil is In and Inder (1997) who used eight vegetable oil i.e. soybean, cottonseed, coconut, sunflower seed, rapeseed, palm, palm kernel, and groundnut oil to see their long-run relationship with each other using cointegration technique. The empirical result reveals the existence of 4 cointegration vector and they suggest that those oils can be grouped according to their end-use consumption. Further, they suggest that a stock buffer scheme is more straightforward.

A different conclusion was reached by Owen et al. (1997) where they found no cointegration relationship between coconut, palm, palm kernel, soybean, and sunflower oil. Using the variance decomposition approach, they found that sunflower and soybean prices can much explain the variation in other oil prices. On the other hand, Alias and Othman (1998) examine the long-run relationship between palm oil and soybean oil using Engle and Granger 2-step approach. Empirical evidence supported the co-movement between both vegetable oil in the long run.

Moreover, the co-movement between vegetable oil and crude oil has been debatable among scholars especially when the recent food crisis 2007-2008 seems to have a great impact on vegetable oil prices. The higher price of crude oil during that period might increase the cost of transportation, machine operation, and fertilizer thus resulting in the increase of food price (Wiggins \& Levy, 2008). Among the scholar who investigates the relationship above are Peri and Baldi (2010) which utilized threshold VECM to investigate the asymmetric effect between conventional diesel and vegetable oil prices (soybean, sunflower seed, and rapeseed oil). Empirical evidence shows that only rapeseed oil has a long-run co-movement with diesel and the adjustment are asymmetric.

Hameed and Arshad (2009) investigate the cointegration relationship between petroleum price and vegetable oil prices namely soybean, palm, rapeseed and sunflower oil. The study utilized a bivariate Engle-Granger approach over the period January 1983 until March 2008. The empirical result shows that long-run co-movement is established between the petroleum price with each of the variables. Meanwhile, Kiatmanaroch and Sriboonchitta (2014) examine the dependence between palm and soybean oil with a condition on the crude oil price. In their study, they conclude that crude oil can affect the dependence structure between palm-soybean oil. 
On the other strand, evidence of literature has focused on the variance analysis which can give useful information regarding the volatility spillover or risk transmission in the agricultural market. One of the empirical studies was Brümmer, Korn, Schlüßler, and Jamali Jaghdani (2016) who found the volatility of oilseeds and vegetable oil are largely driven by its own past volatility. Besides, they also found that palm oil has a strong influence on other edible oils. This has been further supported by $\mathrm{Yu}$, Bessler, and Fuller (2006) who found palm oil initiating the information to other vegetable oil.

Nazlioglu, Erdem, and Soytas (2013) adopted causality in variance test by Hafner and Herwartz (2006) to examine the volatility spillover from crude oil to selected agricultural price (wheat, corn, soybean and sugar). By splitting the sample period into the pre-crisis and post-crisis period, Nazlioglu et al. (2013) found risk transmission is only presence from crude oil to all the variables except sugar in the post-crisis period. In the meantime, Lahiani, Nguyen, and Vo (2013) suggest that investors should take into accounts the variables that have significant volatility spillover among each other to design the portfolio diversification and risk management.

It is important to note that the previous literature on vegetable oil is mainly concern about the analysis in the time domain only. In a practical situation, the relationship between economics, financial and even commodity market could change according to different time horizon or call as frequency domain. The use of wavelet in determining the co-movement across the equity and currency market has been popular nowadays. The use of wavelet in economics can be traced back in 1990s to decompose the economic relationship into different time scale component (Ramsey and Lampart, 1998).

Wavelet coherence technique has been widely used in other fields of studies, among others Madaleno and Pinho (2012) and Al Barghouthi, Qureshi, Ur Rehman, Shahzad, and Qureshi (2017) in the stock market, Kirikkaleli (2020) in political risk, Gallegati (2012) and Kirikkaleli and Athari (2020) in the financial market, Dewandaru et al. (2014) in Islamic and conventional equity indices, Das, Kannadhasan, Al-Yahyaee, and Yoon (2018) in the gold market and Saiti, Ali, Abdullah, and Sajilan (2014), Pal and Mitra (2017) Jiang, Lao, Mo, and Nie (2018) and Cai, Fang, Chang, Tian, and Hamori (2020) in commodity market including vegetable oils markets.

We extend the study on the co-movement between vegetable oil prices by adopting analysis in time-frequency space. The previous study mostly concentrated on the time-series domain without looking at the frequency domain. The relationship between economics, financial and commodity market variables could change according to different time horizon. It is a major concern to see whether the linkages are due to pure contagion or fundamental-based contagion following the recent food crisis 2007-2008 and 2010-2011. Therefore, the study leads to a question of how well the vegetable oils market are integrated? And can investors gain benefit by diversifying their asset in this market?

\section{DATA AND METHODOLOGY}

Monthly price data (nominated in USD per metric tonnes) of major world vegetable oil namely sunflower, rapeseed, soybean and palm oil from January 2003 to March 2018, are used. These data 
are extracted from the International Monetary Fund (2020) and United Nations Conference on Trade and Development (2020). Price of soybean and rapeseed oil are referred to free on board (FOB) ex-mill price in Netherland and FOB price in Rotterdam respectively, while the price of palm oil and sunflower oil are referred to FOB and cost, insurance and freight (CIF) price in NorthWestern Europe port. The sample period of this study starting from 2003 due to availability of the data.

Wavelet method overcomes the limitation of the time series analysis and spectral analysis by analyzing both the time and frequency domain simultaneously. Given the scale and translation properties, non-stationary data is not a problem when dealing with wavelet (Madaleno \& Pinho 2012). In addition, Nguyen and He (2015) documented that wavelet analysis does not require a strong assumption on the data generating process of a given time series. Instead of transforming the price into return series when utilized the wavelet method (see Das et al., 2018; FernandezMacho, 2012; Gallegati, 2012), we are using the price itself (see Saiti et al., 2014; Madaleno \& Pinho, 2012; Floros, 2005) to give the actual picture regarding the price interrelationship among vegetable oils.

There are three types of wavelet transform which are discrete wavelet transform (DWT), maximum overlap discrete wavelet transform (MODWT) and continuous wavelet transform (CWT). DWT is useful to decompose a time series into each different time scale properties and noise reduction (Madaleno \& Pinho, 2012). However, they possess some major drawback which is: 1) the number of observation in DWT require to be $2^{\mathrm{j}}$ - where $\mathrm{j}$ is a number of the scale, 2) DWT is not shiftinvariant and 3) variance of DWT is inefficient (Nguyen \& He, 2015; Najeeb, Bacha, \& Masih, 2015). MODWT is a variant of DWT which is known as non-decimated DWT and time-invariant DWT. Unlike DWT, MODWT can be applied for any given time series length, it is shift-invariant and its variance is much efficient (Nguyen \& He, 2015; Najeeb et al., 2015).

In order to examine the co-movement in time-frequency domain between two distinct time series, the most preferred wavelet transform is the CWT (Das et al., 2018; Abdullah \& Masih, 2016; Najeeb et al., 2015; Dewandaru et al., 2014). The advantage of CWT over the DWT and its variant is CWT can create its own scale based on the length of the observation without the need to define the number of scales (Abdullah \& Masih, 2016). The function of CWT which is $W_{x}(\tau, s)$ is obtained by projecting a 'mother wavelet', $\psi$ into the time series $x(t) \in L^{2}(\mathbb{R})$ which is:

$$
W_{x}(\tau, s)=\int_{-\infty}^{+\infty} x(t) \frac{1}{\sqrt{s}} \psi\left(\frac{t-\tau}{s}\right) d t
$$

Where the wavelet position in time and frequency domain is given by $\tau$ and $s$, respectively. Let $\mathrm{x}$ and $y$ be the pair of any vegetable oil prices which are sunflower, rapeseed, soybean and palm oil. Thus, in order to determine the co-movement of two time series in the time-frequency domain, wavelet coherency technique is utilized with the following function:

$$
R_{n}^{2}(\tau, s)=\frac{\left|S\left(s^{-1} W_{n}^{x y}(\tau, s)\right)\right|^{2}}{S\left(s^{-1} W_{n}^{x}(\tau, s)\right)^{2} \cdot S\left(s^{-1} W_{n}^{y}(\tau, s)\right)^{2}}
$$

where $\mathrm{S}$ denotes the time and scale smoothing parameter. The cross-wavelet transform of $x$ and $y$ series denoted as $W_{n}^{x y}(\tau, s)=W_{n}^{x}(\tau, s) \cdot W_{n}^{y}(\tau, s)$ where $W_{n}^{x}(\tau, s)$ and $W_{n}^{y}(\tau, s)$ are defined as 
continuous wavelet transform for $x$ and $y$ series respectively. The squared wavelet coherence, $R_{n}^{2}(\tau, s)$ are similar with the correlation coefficient whereby the coherence power ranging from 0 (low co-movement) to 1 (high co-movement). The statistical inference regarding the coherency between two individual series depends on the Monte Carlo simulation. Meanwhile, similar with correlation and cross-correlation, the phase difference enables us to differentiate whether both time series $x$ and $y$ move in same direction or different direction or perhaps there are a lead and lag relationship in given time-frequency space. The computation of phase difference can be expressed as equation below:

$$
\phi_{x, y}(\tau, s)=\tan ^{-1} \frac{I\left\{W_{n}^{x y}(\tau, s)\right\}}{\mathbb{R}\left\{W_{n}^{x y}(\tau, s)\right\}}, \quad \phi_{x, y}(\tau, s) \in[-\pi, \pi]
$$

where $I$ and $\mathbb{R}$ denoted as imaginary and real parts respectively. Lead and lag information in the wavelet coherence plot is given by the value of $\phi_{x, y}(\tau, s) \in[-\pi, \pi]$. If the phase difference has a value of 0 , its indicate that both time series move together at the specified frequency. If $\phi_{x, y}(\tau, s) \in$ $\left(0, \frac{\pi}{2}\right)$, then $y$ series leading $x$ series but lagging when $\phi_{x, y}(\tau, s) \in\left(-\frac{\pi}{2}, 0\right)$. Both $x$ and $y$ have anti-phase relation with $y$ leading $x$ if $\phi_{x, y}(\tau, s) \in\left(-\pi,-\frac{\pi}{2}\right)$ while lagging if $\phi_{x, y}(\tau, s) \in\left(\frac{\pi}{2}, \pi\right)$.

For simplicity, the arrow which pointing to right $(\rightarrow) /$ left $(\leftarrow)$ shows both variables move in-phase/ anti-phase. Assume that $x$ will be the first series while $y$ will be a second series in our estimation, the arrow pointing upward $(\uparrow)$, right upward $(\nearrow)$, and left downward $(\swarrow)$ shows the series y lead the x series. Meanwhile, arrow pointing downward $(\downarrow)$, right downward $(\searrow)$ and left upward $(\nwarrow)$ shows the leading of $x$ series over $y$.

Following recent trend in analyzing market integration, this research employs the Wavelet Multiple Correlation (WMC) and Wavelet Multiple Cross-Correlation (WMCC) techniques (FernándezMacho, 2012; Kumar Tiwari, Billah Dar, Bhanja, \& Shah, 2013; Andrieş, Ihnatov, \& Tiwari, 2016). We defined the wavelet coefficients $W_{j t}$ for the respective scales $\lambda_{j}$ in a multivariate stochastic process $X_{t}=\left(x_{1 t}, \ldots, x_{n t}\right)$ to each $x_{i t}$ process by applying MODWT. We also defined WMC, $\varphi_{x}\left(\lambda_{j}\right)$ as a single set of multiscale correlations calculated from a multivariate stochastic process.

At each wavelet scale $\lambda_{j}$, the square root of the regression coefficient of determination in that linear combination of variables $W_{i j t}, i=1,2, \ldots, n$, are calculated for which such coefficient of determination is a maximum. But, practically there are no need to run these auxiliary regressions separately as the coefficient of determination corresponding to the regression of a variable $z_{i}$ on a set of regressors $\left\{z_{k}, k \neq i\right\}$, can be obtained as $R_{i}^{2}=1-\frac{1}{\rho^{i i}}$, where $\rho^{i i}$ is the $i$-th diagonal element of the inverse of the complete correlation matrix $P_{j}$. Therefore, $\varphi_{x}\left(\lambda_{j}\right)$ can be obtained as follow:

$$
\varphi_{x}\left(\lambda_{j}\right)=\sqrt{1-\frac{1}{\max \operatorname{diag} P_{j}^{-1}}}
$$

Where $P_{j}$ is the $(n \times n)$ correlation matrix of $W_{j t}$, and the max $\operatorname{diag}(\cdot)$ operator selects the largest element in the diagonal of the argument. Since the $R_{i}^{2}$ coefficient in the regression of a $z_{i}$ on the 
rest of variables in the system can be shown to be equal to the square correlation between the observed values of $z_{i}$ and the fitted values $\widehat{z_{l}}$ obtained from such regression, we have that $\varphi_{x}\left(\lambda_{j}\right)$ can also be expressed as follow:

$$
\varphi_{X}\left(\lambda_{j}\right)=\operatorname{Corr}\left(W_{i j t}, \widehat{W}_{i j t}\right)=\frac{\operatorname{Cov}\left(W_{i j t}, \widehat{W}_{i j t}\right)}{\sqrt{\operatorname{Var}\left(W_{i j t}\right) \operatorname{Var}\left(\widehat{W}_{i j t}\right)}}
$$

Then, proceed with the Wavelet Multiple Cross-Correlation (WMCC) by allowing lag $\tau$ between the observed and fitted values of the criterion variable at each scale $\lambda_{j}$ as follow:

$$
\varphi_{X}, \tau\left(\lambda_{j}\right)=\operatorname{Corr}\left(W_{i j t}, \widehat{W}_{i j t}\right)=\frac{\operatorname{Cov}\left(W_{i j t}, \widehat{W}_{i j t+\tau}\right)}{\sqrt{\operatorname{Var}\left(W_{i j t}\right) \operatorname{Var}\left(\widehat{W}_{i j t+\tau}\right)}}
$$

Next, we assume that $X=\left[X_{1}, X_{2} \ldots X_{T}\right]$ is a multivariate Gaussian stochastic process realization to develop confidence intervals in the above equation. Then we used the $j$ th order MODWT for individual univariate time series $\left[x_{i 1}, x_{i 2}, \ldots, x_{i T}\right]$ for $i=1,2, \ldots n$ to acquire the wavelet coefficient vectors as follow:

$$
\widetilde{W}_{j}=\left[\begin{array}{lll}
\widetilde{W}_{j 0} & \ldots & W_{j, T-1}
\end{array}\right]=\left[\left(w_{1 j 0}, \ldots, w_{n j 0}\right), \ldots,\left(w_{1 j, \frac{T}{2^{j}}-1}\right)\right] \ldots J
$$

Finally, we are able to obtain the respective confidence interval (CI) for the coefficient of sample wavelet correlation is given as:

$$
C I_{1-\alpha}\left(\varphi x\left(\lambda_{j}\right)\right)=\tanh \left[\tilde{z}_{j} \pm \emptyset_{1-\alpha / 2}^{-1} / \sqrt{\frac{T}{2^{j}}-3}\right]
$$

\section{EMPIRICAL RESULT}

Descriptive statistics of a monthly price for major world vegetable oil is presented in Table 1 . The data is ranging from January 2003 until March 2018 give a total of 183 number of observations. The mean price of sunflower oil is about $\$ 944$ per metric tonnes which is a bit higher compared to other edible oil. Palm oil shows the lowest average price at $\$ 730$ per metric tonnes. Maximum price of soybean, sunflower, palm and rapeseed are \$1537, \$2045, \$1292 and \$1577 per metric tonnes respectively.

It is interesting to note that all the vegetable oil except palm oil reach their higher price during June 2008. It could be due to the fact of global food crisis 2007-2008 that's has pushed up the price. Besides, in August 2008 all vegetable oil prices experienced their lowest price except for soybean oil during the period of study. Moreover, a high value of the standard deviation of sunflower oil is expected as it's offered a high price. All vegetable oil prices has a positively skewed distribution which indicates that the increase in price is more often compared to decrease in price. Last but not least, soybean, palm and rapeseed oil have a platykurtic distribution since the value of kurtosis is less than 3 while sunflower oil shows a leptokurtic distribution. 
Table 1: Descriptive Statistics of Monthly Price for the Vegetable Oils.

\begin{tabular}{ccccc}
\hline \hline Measures & Soybean & Sunflower & Palm & Rapeseed \\
\hline Mean & 880.0656 & 943.7172 & 730.2568 & 930.5287 \\
Median & 837.0000 & 843.0000 & 716.0000 & 853.0000 \\
Maximum & 1537.0000 & 2045.0000 & 1292.0000 & 1577.0000 \\
Minimum & 497.0000 & 543.0000 & 395.0000 & 552.0000 \\
Std. Dev. & 259.8028 & 303.4308 & 232.8042 & 248.4869 \\
Skewness & 0.5286 & 1.2471 & 0.4328 & 0.8034 \\
Kurtosis & 2.4034 & 4.3185 & 2.3755 & 2.6763 \\
\hline \hline
\end{tabular}

Figure $3 \mathrm{a}$ to Figure $3 \mathrm{f}$ show a contour plot of wavelet cross coherency and phase difference among soybean, sunflower, palm and rapeseed oil. The lighter line forming the boundary in the coherence maps shows the cone of influence where the edges effect takes place while the black contour plot indicates 5\% statistical significance. At first glance, we can see that there is high co-movement among vegetable oil understudy especially in high scales (low frequency) since there is a lot of arrow pointing to the right.

Figure 3a shows that sunflower leads the soybean for the period between 2003 until mid-2004 in the 2-8 months but lagging during the year 2005 in a scale of 2-4 month. During food crisis 20072008 , contagion is present due to common shocks which can be described by the sudden increase in the coherence power from low (blue) to high (red) with soybean leading the sunflower oil in a scale of 2-16 months. Nevertheless, the effect is much likely to be pronounced in the 16-64 months scale. The increase of coherence in both low and high scales suggesting the linkages between soybean and sunflower oil are due to both contagion and interdependence.

Moreover, the impact of food crisis 2010-2011 is also detected in the low scale coherence between 2010 until 2012. However, the impact is much smaller compared to the food crisis during 20072008. Furthermore, on the co-movement for the year 2013 onwards, the linkages between soybean and sunflower oil in low scales show a relatively lower coherence except for the period of 2015 in 4-8 months and 2017 in 2-4 months where the co-movement seems to be strong with soybean lead the sunflower oil. 
Figure 3a: Wavelet Cross Coherency and Phase Difference Plot Between Soybean and Sunflower Oil 2004 to 2018.

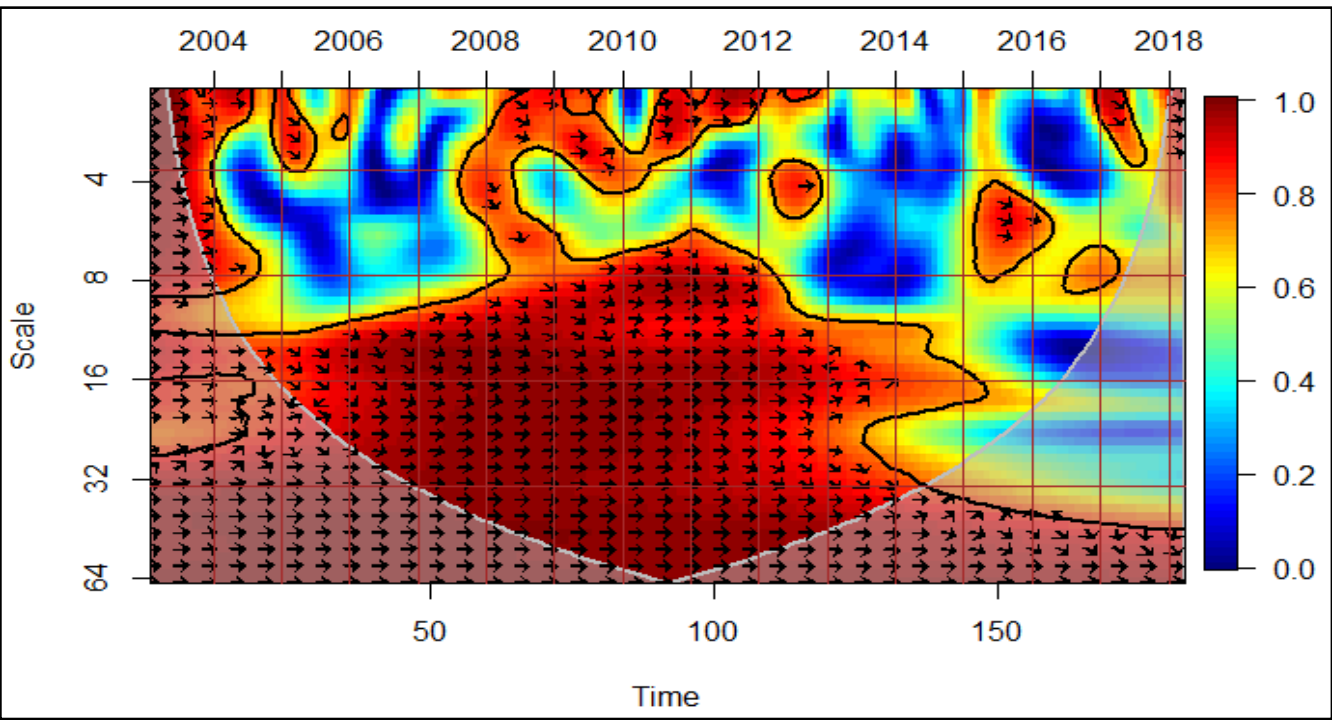

Figure 3b: Wavelet Cross Coherency and phase difference plot between Soybean and Palm oil 2004 to 2018.

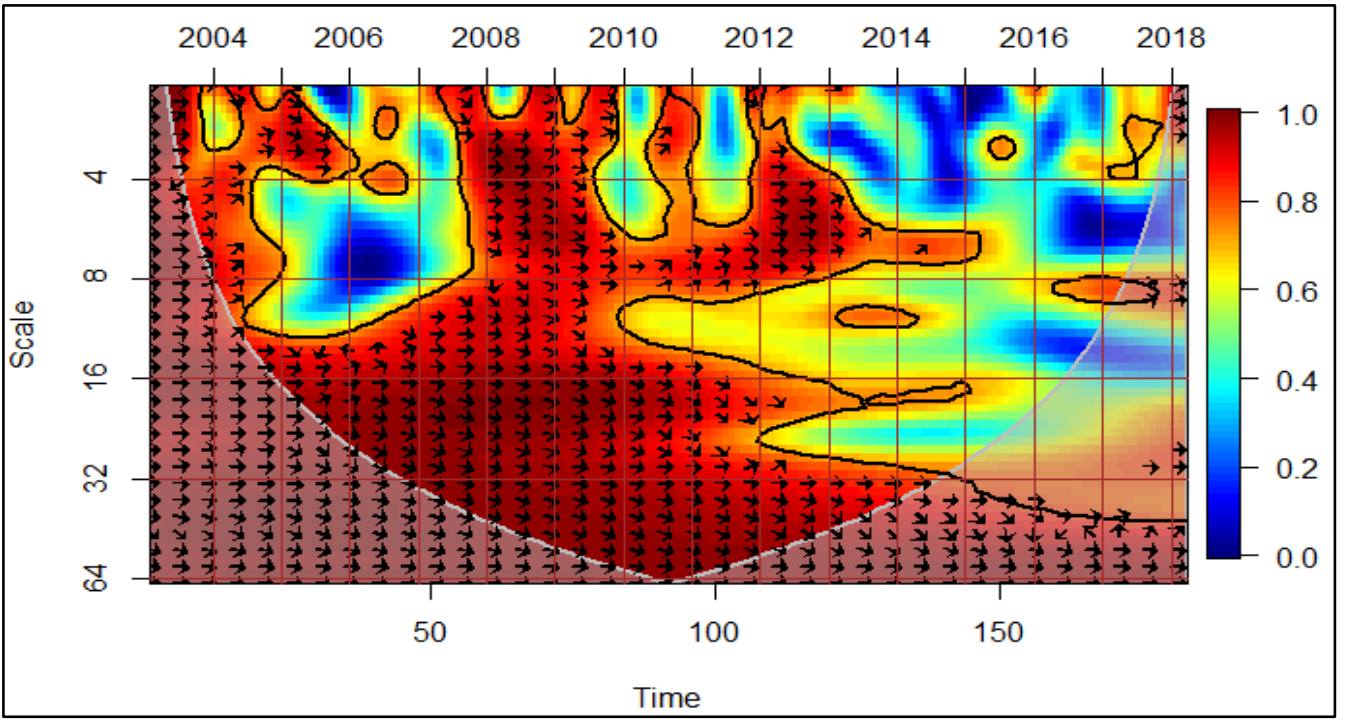

Turning to the cross-coherence plot between soybean and palm oil (Figure 3b), palm oil seems to lead soybean oil during 2003 until 2004 in 2-8 months but lagging during 2005 in scale of 2-4 months. Compared to others coherence plot, the immediate increase in coherency between soybean and palm oil are pronounced as early as 2007 with the soybean lead the palm oil price in $2-4$ 
months. The impact of the crisis is continuous from the low scale to high scale suggesting the strong co-movement are due to pure contagion and fundamental-based contagion. On the other hand, the food crisis 2010-2011 only have a smaller impact on the linkages between soybean and palm oil. Generally, for the high scales component (16-64 months), soybean seems to lead palm oil price between the period 2006 until 2013 while in low scale (2-16 months) there is a mixture of leading and lagging between the two variables. Besides, from the plot of the coherence, soybean and palm oil show a weaker co-movement in all scales.

The wavelet cross-coherency plot between soybean and rapeseed oil price (Figure 3c) also shows interesting findings. Comparing the coherence plot of soybean-rapeseed with the soybeansunflower and soybean-palm, there is no lead and lag relationship during period of 2003 and 2005 in the 2-8 months scales. However, during 2007, there is evidence of soybean oil lead the rapeseed oil in 4-8 months. The sudden increase of coherence between those oil in 2-4 months scales can be detected in early 2009 thus proving the contagion effect due to the food price crisis.

Besides, contrary to other coherence plots, the co-movement of soybean and rapeseed oil prices (Figure 3c) in scales 16-64 months are found to be completely integrated suggesting higher interdependence among them. In facts, recent data also shows some increase in the co-movement in low scales. It is worth to note that food crisis 2010-2011 generally have a big impact on the comovement between soybean and rapeseed oil compared to the earlier crisis. In addition, the comovement of sunflower and palm oil price is found during period of 2003 until early 2005 in the 2-4 months scale.

Figure 3c: Wavelet Cross Coherency and phase difference plot between Soybean and Rapeseed oil 2004 to 2018 .

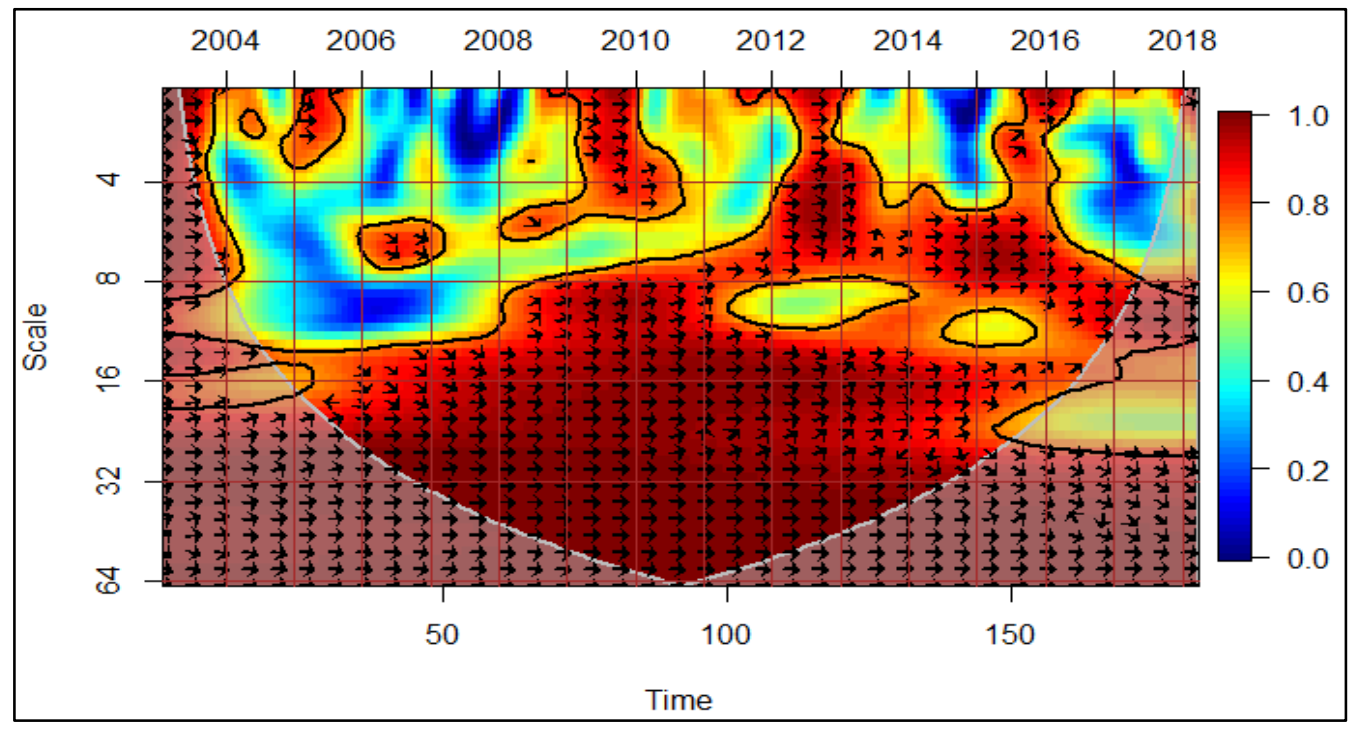


Following the global food crisis, the impact towards the co-movement of sunflower-palm can only be seen in 2008 with palm oil price lead the sunflower oil price in 4-8 months (Figure 3d). Large coherency area in the high scale wavelet for the period of 2007 until 2011 indicate the fundamentalbased contagion among those oils. On the other hand, the significant of contour plot with a rightdownward arrow in 2009 and 2012 shows the leading of sunflower oil price over the palm oil price. While the period of 2006 until 2012 shows a high coherence, more recent data shows that sunflower and palm oil price has a relatively weaker coherence especially in the high scale.

Figure 3d: Wavelet Cross Coherency and phase difference plot between Sunflower and Palm oil 2004 to 2018.

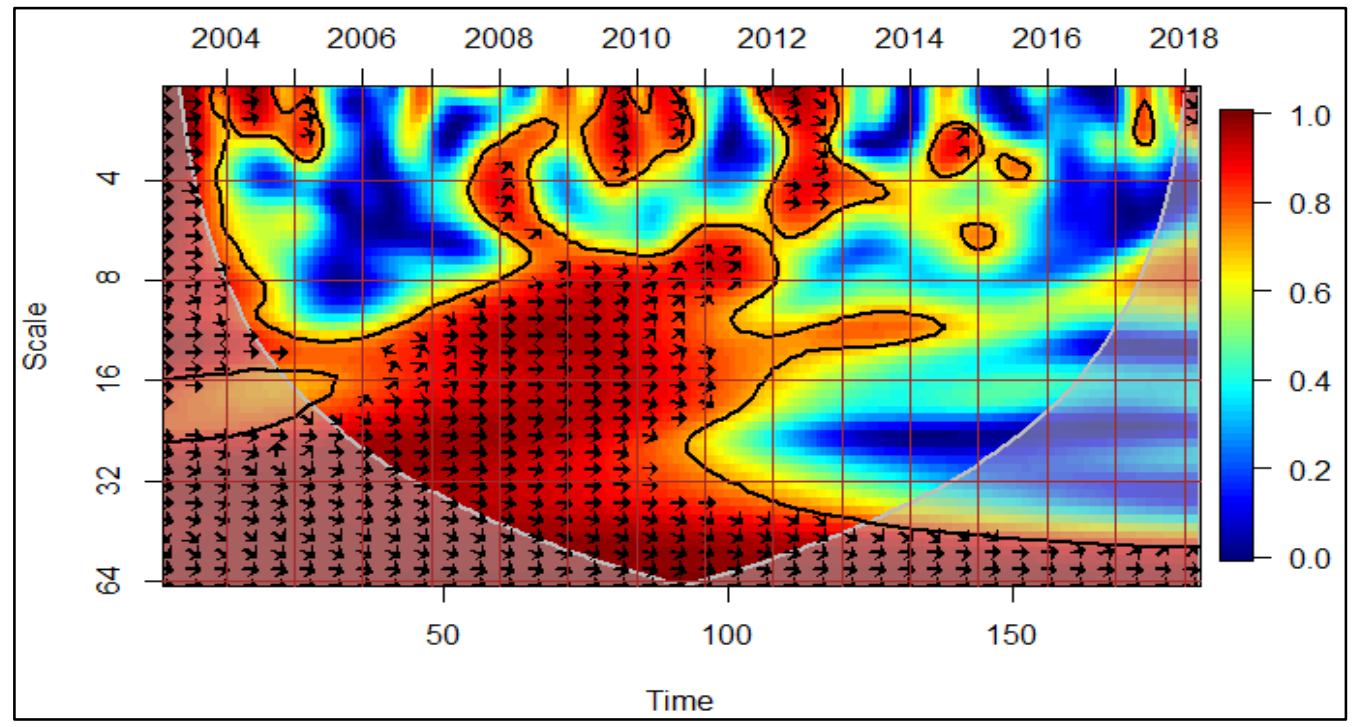

At a glance, coherence maps of sunflower and rapeseed oil price (Figure 3e) show a lot of arrow pointing to the right which indicated both variable moves in phase. The co-movement between sunflower and rapeseed oil in 2-8 months scale is higher during 2003 before its vanished after 2006. Moreover, the impact of food crisis on the co-movement in 2-4 month can be seen on year 2009 which is the same pattern in coherence of soybean and rapeseed. Meanwhile, between period 2007 until 2010 for scale 8-16 months, rapeseed oil leads the sunflower oil and its continue until 2011 for the scale of 4-8 months.

The co-movement in low scales also can be detected during 2012 where both variable move in phase together. The large coherency area especially in the high scale is suggesting evidence of a strong interdependence between both sunflower and rapeseed oil. Finally, the last plot shows the co-movement between the palm and rapeseed oil in time-frequency space (Figure $3 \mathrm{f}$ ). Result from coherence maps shows a sudden increase in the coherence during the period of 2009 due to the food crisis. Palm oil seems to lead the rapeseed oil in scale 4-8 months during period of 2010-2011 and 2014 while lagging in scale 2-4 months on 2014. The evidence of interdependence between palm and rapeseed only occur during 2006 until 2014 while the contagion mostly pronounced during 2010 until 2015. 
Figure 3e: Wavelet Cross Coherency and phase difference plot between Sunflower and Rapeseed oil 2004 to 2018.

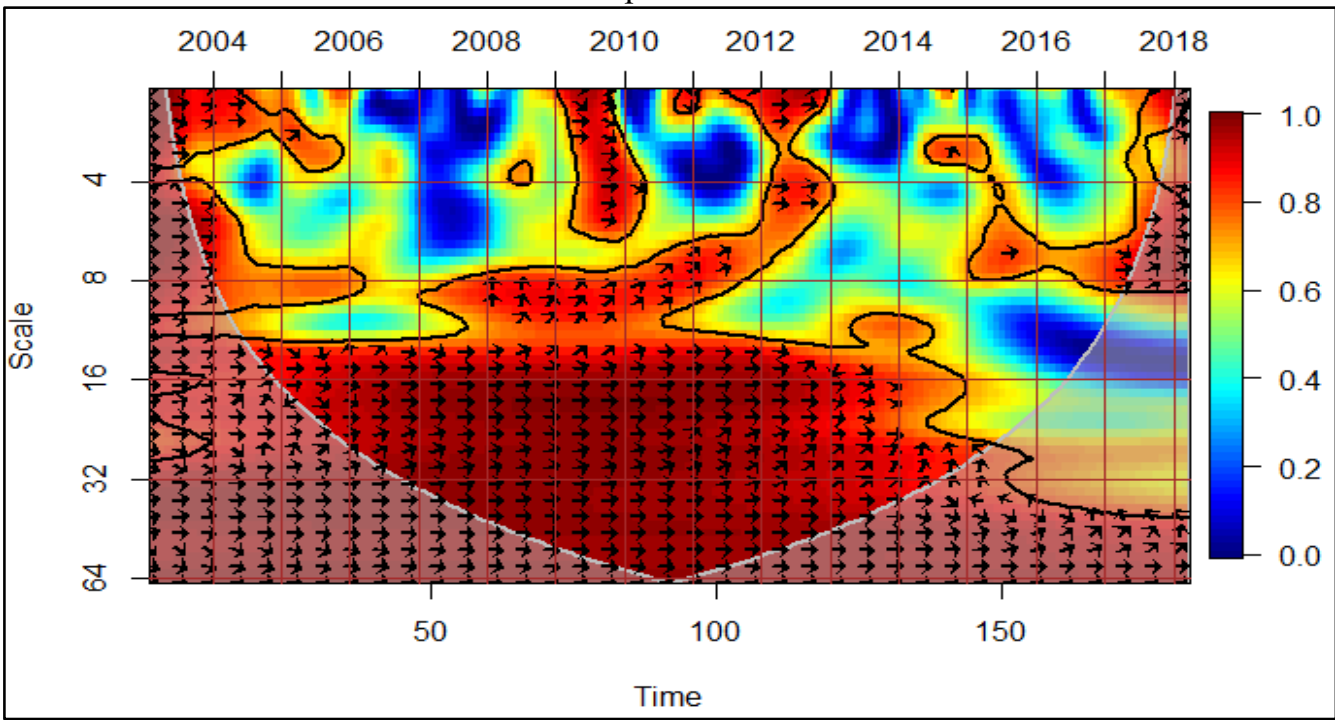

Figure 3f: Wavelet Cross Coherency and phase difference plot between Palm and Rapeseed oil 2004 to 2018.

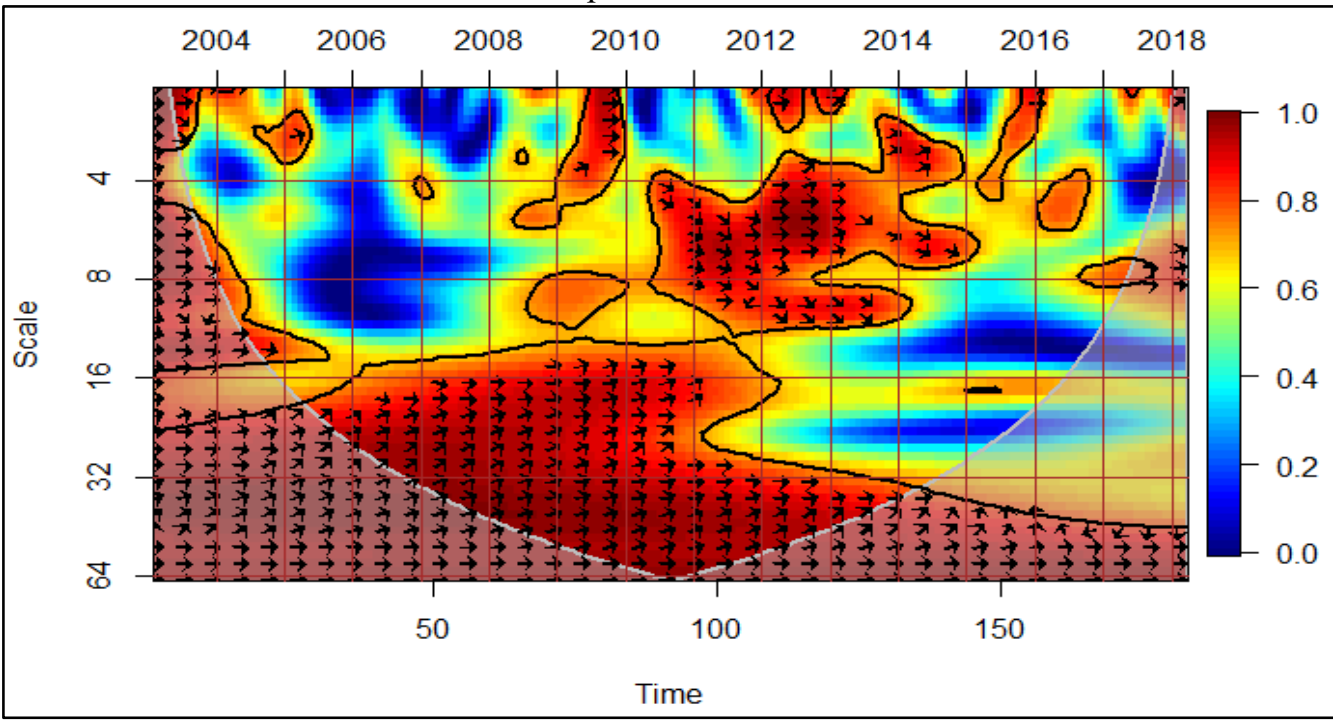

Figure 4 shows the result of the contemporaneous correlation between all vegetable oil from the estimation of Wavelet Multiple Correlation. From the figure above, correlation tends to increase over the scale which the result in accordance with the finding by wavelet coherence whereby each of the bivariate correlation increases as horizon increase. In particular, correlation coefficient at 
D1 (2-4 months) is $0.799, \mathrm{D} 2$ (4-8 months) is $0.825, \mathrm{D} 3$ (8-16 months) is 0.954 and D4 (16-32 months) is 0.992 . This indicates that the vegetable oil market is perfectly integrated especially in the long run. The detail of the correlation coefficient with their corresponding confidence interval in Table 2.

Figure 4: Wavelet Multiple Correlation for all vegetable oil.

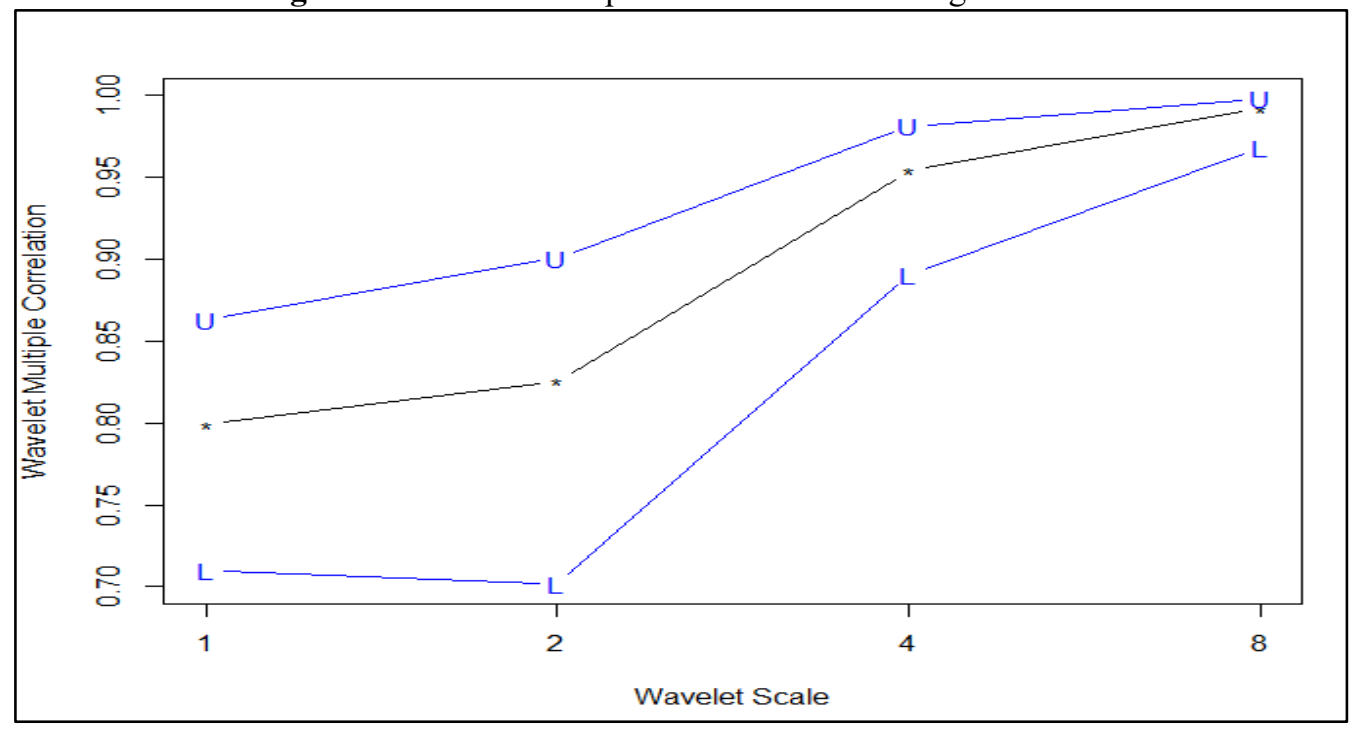

Notes: The blue line corresponds to the upper and lowers bound of $95 \%$ confidence interval.

Table 2: Wavelet Multiple Correlation among Vegetable Oil.

\begin{tabular}{cccc}
\hline \hline Scales & L & Cor & U \\
\hline D1 & 0.710 & 0.799 & 0.863 \\
D2 & 0.702 & 0.825 & 0.901 \\
D3 & 0.890 & 0.954 & 0.981 \\
D4 & 0.968 & 0.992 & 0.998 \\
\hline \hline
\end{tabular}

Notes: Cor = Correlation coefficient, $\mathrm{U}=$ Upper bound of $95 \%$ confidence interval and $\mathrm{L}=$ Lower bound of $95 \%$ confidence interval.

Figure 5 shows the result of wavelet multiple cross-correlation for different wavelet scale with lead and lag up to 3 years (36 months). The overall graph shows that multiple correlation tends to increase as the horizon are increasing which the result in accordance with the wavelet cross coherency. Wavelet level 1 shows the horizon for 2-4 months. From the graph, positive lags are not significant or just marginally significant between 3 and 36 months. However, negative lags are not significant between 16 months and 36 months. In this level, soybean oil seems to be a potential leader for vegetable oil market prices for the horizon of 2-4 months.

Meanwhile, level 2 shows the horizon for 4-8 months whereby positive lags are not significant or just marginally significant between 5 and 36 months. However, the negative lags of the crosscorrelation are not significant between 4 months and 36 months. For this level, soybean oil also 
acts as a potential leader in world vegetable oil market prices. In addition, wavelet level 3 and level 4 shows that the cross-correlations are much higher compared to level 1 and level 2 . Wavelet level 3 which correspond to horizon of 8-16 months shows that cross-correlation in negative lags are more significant compared to positive lags especially for lag below than 12 months (1 year) while wavelet level 4 which correspond to horizon of 16-32 months shows that cross-correlation in both positive and negative lags are all significant except for period between 12 months and 24 months. Both wavelet level shows that soybean still becoming the potential leader in the vegetable oil market for the horizon of 8-32 months.

Figure 5: Wavelet Multiple Cross-Correlation among Soybean, Sunflower, Palm and Rapeseed oil for different wavelet scales

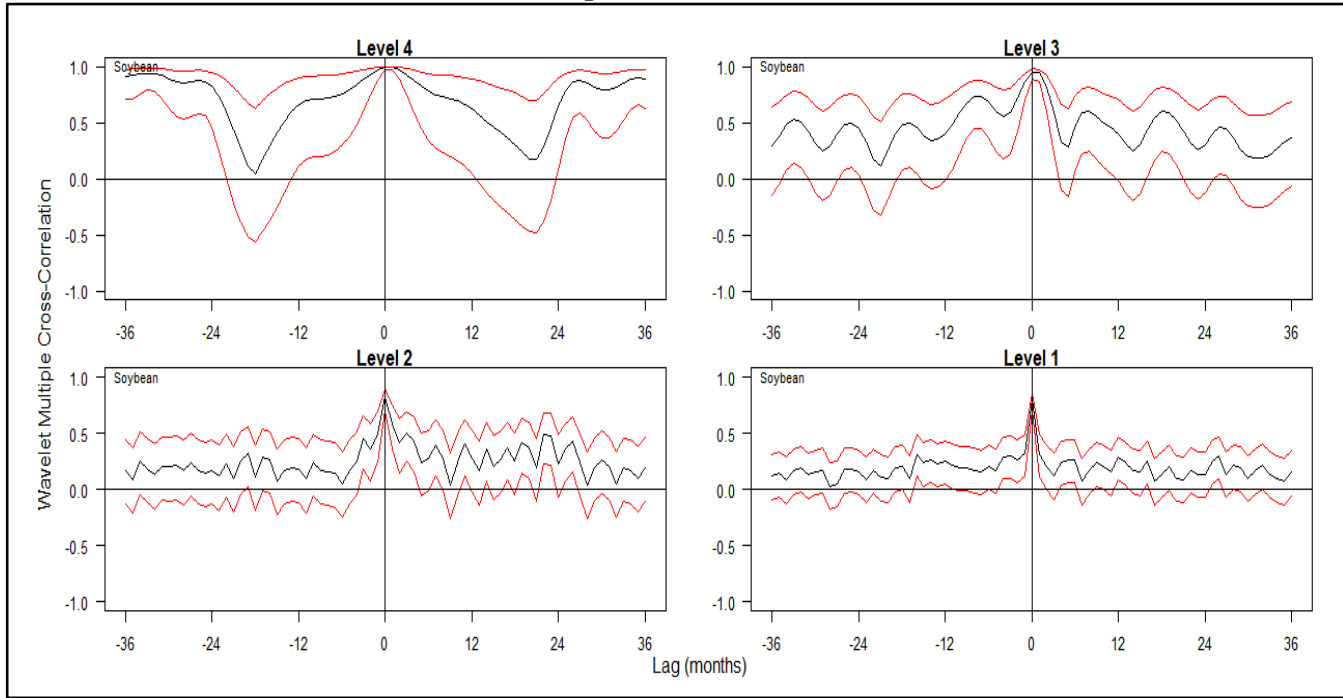

Notes: Upper right corner shows the potential leader and the red line corresponds to the upper and lower bound of $95 \%$ confidence interval.

We further the analysis by eliminating soybean oil price from the WMCC analysis to confirm what is the next vegetable oil leader in different time scales after soybean oil. Figure 6 shows the result of WMCC using three vegetable oil namely sunflower, palm, and rapeseed oil. Based on the upper right corner of each figure, palm oil leads other vegetable oil for the wavelet level 1 and 2 while sunflower lead the other vegetable oil for wavelet level 3 and 4. In conclusion, results from wavelet multiple cross-correlations conclude that soybean oil price has a greater influence on the price of world vegetable oil followed by palm oil especially in level 1 and 2 .

This result is in accordance with the finding by Amiruddin, Abrahman, and Shariff (2005) who find that soybean oil is the leader of other vegetable oil by using the Vector Error Correction Model (VECM). Besides, they also suggest that palm oil is the number two vegetable oil that influences other vegetable oil prices. However, their analysis is focusing on the time domain only but not the frequency domain. Thus, considering only the time domain could have a misleading conclusion. 
Figure 6: Wavelet Multiple Cross-Correlation among Sunflower, Palm, and Rapeseed oil for different wavelet scales.

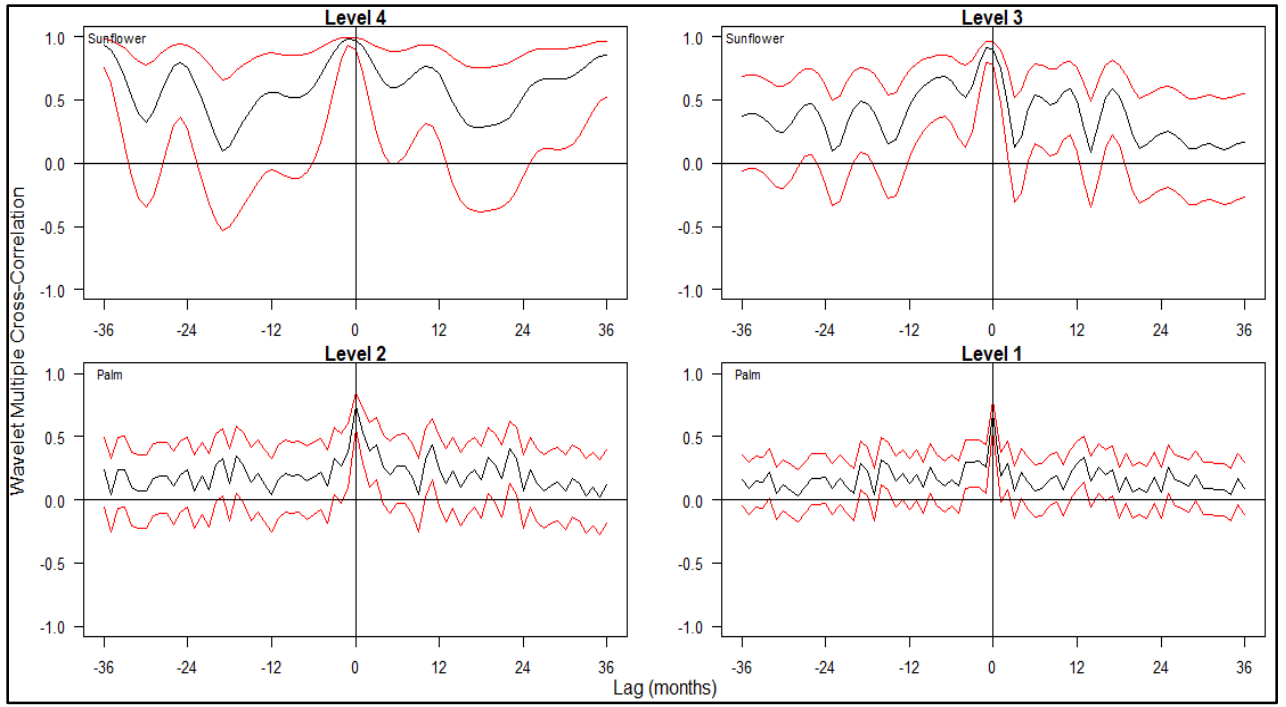

Notes: Upper right corner shows the potential leader and the red line corresponds to the upper and lower bound of $95 \%$ confidence interval.

\section{CONCLUSION}

Literature has documented that the co-movement among vegetable oil prices itself or vegetable oil with other commodities like crude oil. However, the evidence is rather mixed than unique which may depend on the econometric technique, data spanning, and variables that have been used. This paper aimed to investigates the co-movement among world vegetable oil prices using the timefrequency domain known as a wavelet. The major drawback of the previous studies is analyzing the data in the time or frequency domain independently. Instead, there could be some significant relation between two or multiple series at a certain time with a certain frequency.

Following the idea by Orlov (2009) and Bodart and Candelon (2009), we find strong linkages between major world vegetable oil prices are due to contagion and interdependence. Moreover, palm oil price shows weaker co-movement with other edible oil prices recently but more recent data shows evidence of increasing linkages between soybean and rapeseed oil prices. The impact of the food crisis on the co-movement between rapeseed and other vegetable oil prices are actually more delayed especially in the low scale component. However, soybean and palm oil show early stronger linkages during the crisis and this might be due to both vegetable oil are the major producer. Thus, it might incur an increase in the cost of operation due to a sharp increase in crude oil prices. Furthermore, the result from multiple wavelet cross-correlations concludes that soybean oil is the potential leader of the world vegetable oil market in all horizons. Thus, the ups and downs in the price of soybean oil have an impact on other vegetable oil.

Generally, the strong linkages between vegetable oil especially in the high scale maybe attribute to end users since they are close substitutes, especially when it comes to cooking. The end-user 
consumers might be affected by the price fluctuation between vegetable oil; thus they prefer to consume other vegetable oil products in order to maximize their utility. Therefore, in the long-run vegetable oil is likely to co-move with each other. However, this scenario could be different from the side of importer or producers since they are required to produce the product based on the ingredient that specifically depends on the chemical and physical properties of the vegetable oil use. The difference in terms of cost of processing and refining of each vegetable oils and lower interchangeability especially in the production may indicate weaker co-movement among vegetable oil on the lower scale. As a conclusion to our finding, we conclude that the existence of incomplete vegetable oil market integration among major world vegetable oil producer with the soybean oil leads the price.

Since there is evidence pointing toward soybean price as the leading variable, thus policymakers and industry players could use this information to forecast the movement of other vegetable oil prices and formulate the corresponding strategies to maximize profit and minimize risk. From the perspective of investment, the wavelet approach in our analysis can decompose the series into multiple different horizons (2-4 months, 4-8 months, 8-16 months, 16-32 months, and 32-64 months). Given that the players in the market are coming from various background, information regarding the frequency domain are much concern. Generally, investors in vegetable oil markets could not be beneficial in diversifying more than one asset in the vegetable oil market. However, it could be practical especially for investors who concern about the low scale component. Interestingly, palm oil seems to be less integrated with other vegetable oil recently making it is a useful tool for diversifying assets. Future research can be done by utilizing the high-frequency data like minute, hourly or daily data in order to gain more useful information on the low scale part.

\section{ACKNOWLEDGEMENT}

This research is funded by Geran Kursi Endowmen MPOB-UKM EP-2018-007. This paper was written before Abdul Hafizh joined the Bank Negara Malaysia.

\section{REFERENCES}

Abdullah, A. M., \& Masih, A. M. M. (2016). Diversification in crude oil and other commodities: A comparative analysis. Asian Academy of Management Journal of Accounting and Finance, 12(1), 101-128.

Al Barghouthi, S., Qureshi, S., Ur Rehman, I., Shahzad, F., \& Qureshi, F. (2017). Consumer Confidence and Sectoral Stock Returns in China: Evidence from Multiresolutions Wavelet and Granger Coherence Analyses. International Journal of Business and Society, 18(3), 479-502.

Alias, M. H., \& Othman, J. (1998). Cointegration Between Palm Oil Price and Soybean Oil Price: A Study on Market Integration. Jurnal Ekonomi Malaysia, 32, 39-50.

Amiruddin, M. N., Abrahman, A. K., \& Shariff, F. (2005). Market potential and challenges for the Malaysian palm oil industry in facing competition from other vegetable oils. Oil Palm Industry Economic Journal, 5(1), 17-27.

Andrieş, A. M., Ihnatov, I., \& Tiwari, A. K. (2016). Comovement of Exchange Rates: A Wavelet Analysis. Emerging Markets Finance and Trade, 52(3), 574-588. 
Bodart, V., \& Candelon, B. (2009). Evidence of interdependence and contagion using a frequency domain framework. Emerging Markets Review, 10(2), 140-150.

Brümmer, B., Korn, O., Schlüßler, K., \& Jamali Jaghdani, T. (2016). Volatility in Oilseeds and Vegetable Oils Markets: Drivers and Spillovers. Journal of Agricultural Economics, 67(3), 685-705.

Cai, X. J., Fang, Z., Chang, Y., Tian, S., \& Hamori, S. (2020). Co-movements in commodity markets and implications in diversification benefits. Empirical Economics, 58(2), 393-425.

Calvo, S., \& Reinhart, C. (1996). Capital Flows to Latin America: Is There Evidence of Contagion Effects? In Calvo, M., Goldstein, M., \& Hochreiter, E. (Eds.), Private Capital Flows to Emerging Markets After the Mexican Crisis, Institute for International Economics, NY: Washington

Coulibaly, A. L. (2013). The Food Price Increase of 2010-2011: Causes and Impacts. Library of Parliament: Ottawa, Canada.

Das, D., Kannadhasan, M., Al-Yahyaee, K. H., \& Yoon, S. M. (2018). A wavelet analysis of comovements in Asian gold markets. Physica A: Statistical Mechanics and Its Applications, 492, 192-206.

Dewandaru, G., Rizvi, S. A. R., Masih, R., Masih, M., \& Alhabshi, S. O. (2014). Stock market comovements: Islamic versus conventional equity indices with multi-timescales analysis. Economic Systems, 38(4), 553-571.

Fernández-Macho, J. (2012). Wavelet multiple correlation and cross-correlation: A multiscale analysis of Eurozone stock markets. Physica A: Statistical Mechanics and Its Applications, 391(4), 1097-1104.

Floros, C. (2005). Price Linkages Between the US, Japan and UK stock markets. Swiss Society for Financial Market Reseacrh, 19(2), 169-178.

Gallegati, M. (2012). A wavelet-based approach to test for financial market contagion. Computational Statistics and Data Analysis, 56(11), 3491-3497.

Hafner, C. M., \& Herwartz, H. (2006). A Lagrange multiplier test for causality in variance. Economics Letters, 93(1), 137-141.

Hameed, A. A. A., \& Arshad, F. M. (2009). The impact of petroleum prices on vegetable oils prices: Evidence from cointegration tests. Oil Palm Industry Economic Journal, 9(2), 3140.

In, F., \& Inder, B. (1997). Long-run relationship between world vegetable oil prices. The Australian Journal of Agricultural and Resource Economics, 41(4), 455-470.

International Monetary Fund (IMF) (2020). IMF Primary Commodity Prices. Retrieved Mar 19, 2020, from http://www.imf.org/external/np/res/commod/index.aspx.

Jiang, Y., Lao, J., Mo, B., \& Nie, H. (2018). Dynamic linkages among global oil market, agricultural raw material markets and metal markets: An application of wavelet and copula approaches. Physica A: Statistical Mechanics and Its Applications, 508, 265-279.

Johansen, S., \& Juselius, K. (1990). Maximum Likelihood Estimation and Inference on Cointegration--with Applications to the Demand for Money. Oxford Bulletin of Economics \& Statistics, 52(2), 169-210.

Kiatmanaroch, T., \& Sriboonchitta, S. (2014). Dependence Structure between Crude Oil, Soybeans, and Palm Oil in ASEAN Region: Energy and Food Security Context. In Huynh, V. N., Kreinovich, V., \& Sriboonchitta, S. (Eds.), Modeling Dependence in Econometrics, (pp. 329-341). New York, Springer.

Kirikkaleli, D. (2020). Does political risk matter for economic and financial risks in Venezuela?. Journal of Economic Structures, 9(3), 1-10. 
Kirikkaleli, D., \& Athari, S. A. (2020). Time-frequency Co-movements between Bank Credit Supply and Economic Growth in an Emerging Market: Does the Bank Ownership Structure Matter. The North American Journal of Economics and Finance, 54, 101239.

Kumar Tiwari, A., Billah Dar, A., Bhanja, N., \& Shah, A. (2013). Stock market integration in Asian countries: Evidence from wavelet multiple correlations. Journal of Economic Integration, 28(3), 441-456.

Lahiani, A., Nguyen, D. K., \& Vo, T. (2013). Understanding return and volatility spillovers among major agricultural commodities. Journal of Applied Business Research, 29(6), 1781-1790.

Madaleno, M., \& Pinho, C. (2012). International Stock Market Indices Comovements: A New Look. International Journal of Finance \& Economics, 17(2), 89-102.

Najeeb, S. F., Bacha, O., \& Masih, M. (2015). Does heterogeneity in investment horizons affect portfolio diversification? Some insights using M-GARCH-DCC and Wavelet correlation analysis. Emerging Markets Finance and Trade, 51(1), 188-208.

Nazlioglu, S., Erdem, C., \& Soytas, U. (2013). Volatility spillover between oil and agricultural commodity markets. Energy Economics, 36, 658-665.

Nguyen, T., \& He, T.-X. (2015). Wavelet Analysis and Applications in Economics and Finance. Journal of of Statistics and Mathematical Sciences, 1(1), 22-37.

Orlov, A. G. (2009). A cospectral analysis of exchange rate comovements during Asian financial crisis. Journal of International Financial Markets, Institutions and Money, 19(5), 742-758.

Owen, A. D., Chowdhury, K., \& Garrido, J. R. R. (1997). Price interrelationships in the vegetable and tropical oils market. Applied Economics, 29(1), 119-124.

Pal, D., \& Mitra, S. K. (2017). Time-frequency contained co-movement of crude oil and world food prices: A wavelet-based analysis. Energy Economics, 62(2017), 230-239.

Peri, M., \& Baldi, L. (2010). Vegetable oil market and biofuel policy: An asymmetric cointegration approach. Energy Economics, 32(3), 687-693.

Ramsey, J. B., \& Lampart, C. (1998) Decomposition of economic relationships by timescale using wavelets, Macroeconomic Dynamics, 2(1), 49-71.

Saiti, B., Ali, A., Abdullah, N., \& Sajilan, S. (2014). Palm Oil Price, Exchange Rate, and Stock Market: A Wavelet Analysis on the Malaysian Market. Eurasian Journal of Economics and Finance, 2(1), 13-27.

United Nations Conference on Trade and Development. (2020). Commodity Prices, Monthly. Retrieved Mar 19, 2020, from http://unctadstat.unctad.org/wds/TableViewer /tableView.aspx?ReportId=140866.

United States Department of Agriculture. (2018). Oilseeds: World Markets and Trade. Washington, DC: US Department of Agriculture.

Wiggins, S., \& Levy, S. (2008). Rising food price: A global crisis. London: Overseas Development Institute.

Yu, T. H., Bessler, D. A., \& Fuller, S. W. (2006, July 23-26). Cointegration and Causality Analysis of World Vegetable Oil and Crude Oil Prices. Paper presented in the American Agricultural Economics Association Annual Meeting, Long Beach, California. doi: 10.22004/ag.econ.21439 